\title{
Walking the Talk: Mandatory Energy Efficiency in all Buildings in South Africa
}

\author{
Kola O. Odeku \\ Faculty of Management and Law, University of Limpopo, Turfloop, South Africa
}

\section{Doi:10.5901/mjss.2014.v5n20p3048}

\begin{abstract}
This article looks at the recently promulgated energy efficiency standard and code for buildings in South Africa. Energy efficiency intervention becomes imperative in view of the fact that South Africa is vulnerable to the impact of climate change. Although numerous interventions have been put in place and being implemented by the government to achieve a sustainable energy use, none compelled energy efficiency in buildings until when the government introduced the Energy Efficiency code in buildings. This article examines the significance of the code and the standards set for energy efficiency and other alternative energy; what it sets out to achieve; and the support needed to realise the overarching provisions of the code.
\end{abstract}

Keywords: Energy efficiency, Buildings, Code, Sustainability, Threats, Implementation

\section{Introduction}

As part of the solution to various environmental problems attributed to emissions of noxious gasses to the environment, there have been numerous strategic interventions to address these problems and of recent, this South African standard was approved by the National Committee StanSA SC 5120.61K, Construction Standards - Energy Efficiency in Buildings, in accordance with procedures of Standards South Africa, in compliance with Annex 3 of the WTO/TBT agreement (Warburton et al., 2007). Also, the Department of Energy in South Africa has introduced a policy to support the Energy Efficiency and Demand Side Management Program for the Electricity Sector through the Standard Offer Incentive Scheme (EEDSMP, 2010). The scheme, in terms of Section 7(1), covers a whole range of buildings including, but not limited to, "all government-owned buildings (particularly hospitals and clinics, prisons, military barracks, offices etc.) and private residential dwellings. Commercial buildings targeted under this program include offices, hotels and other hospitality facilities, employee compounds at mines, refineries and power stations etc."

Furthermore, the scheme also covers "existing housing developments, and SWH, ceiling insulation and efficient lighting shall be the key interventions and stipulates that generally, interventions in respect of the building envelope shall include efficient lighting, insulation improvement, more efficient HVAC systems, installation of lighting and motion sensors etc." With regard to energy efficiency in new and old buildings, the view has been expressed that "a strategy for improved energy efficiency of existing buildings is a necessity if the energy consumption is to be reduced significantly over a limited period of time. The life time of buildings ranges from 50 to 100 years and the improvement of the existing building stock will thus have much higher impact than the tightening of requirements for new buildings. "A building has a long life cycle, so its effect on the environment is a long and continuing issue to consider" (ASPO, 2008). Pursuant to this, the EEDSMP, 2010, by recognising the significance of impact of the energy used and consumed in old buildings, made it compulsory for any improvement or renovations to existing buildings to be energy efficient (Costa et al. 2013). In addition, it also mandates them to convert to energy-efficiency buildings. Explaining the significance of energy efficiency and development, Sebitosi (2008:1591) points out that "energy efficiency has become recognised as one of the most costeffective ways of meeting the demands of sustainable development. It has been aptly referred to as the best energy resource."

\section{The Significance of Energy Efficiency in Housing}

South Africa is currently facing a major energy challenge because fossil fuel is becoming scarcer (Pegels, 2010). As Pegels (2010:4945) aptly points out that: "The challenge of transforming entire economies is enormous; even more so if a country is as fossil fuel based and emission intensive as South Africa. However, in an increasingly carbon-constrained world and already now facing climate change impacts South Africa has to reduce greenhouse gas emissions intensity soon and decidedly." 
A lot of foreign exchange earnings of the country are being spent on importation of the products (Davidson \& Sokona, 2002). At home, it is becoming more expensive to produce, and the worse aspect of it all is that emissions from fossil fuels are responsible for global warming and climate change (Simms \& Murphy, 2005). "Climate change is one of this century's most serious problems. The Fourth Assessment Report of the Intergovernmental Panel on Climate Change (IPCC) points to human activity as one of the major causes of global warming. Business-as-usual may lead to a disastrous transformation of the planet, and recent scientific findings emphasize the growing urgency of reducing greenhouse gas emissions"(Pegels, 2010: 4945).

Against the backdrop of these environmental hazards and the challenges they pose, it becomes very important to tap into the huge potential of energy efficiency as an alternative approach to huge reliance on fossil fuels. From the supply side, it is apparent that supplies of fossil fuels such as oil, gas and coal are becoming scarcer these days, thereby resulting in increases in prices (Brecha, 2008). This is a signal to all consumers that the days of cheap oil and gas are coming to an end (Rotmans, 1997). More importantly, scientific opinions have admonished that global climate change is caused by human activities such as burning fossil fuels that have disastrous effects and consequences on the environment and human beings (Dryzek, 2013). They have also warned that if these activities are left unchecked, they will aggravate the already tense environmental problems (Clapp \& Dauvergne, 2008). With regard to the South African footprint, "even though the contribution of South Africa to total global emissions is still moderate (1.1per cent in 2005), its per capita emission rate of 9 tonnes $\mathrm{CO}_{2}$ per person in 2005 was above the global average of 5.8 tonnes and more than six times higher than the sub-Saharan average of 1.4 tonnes, in order to maintain and sustain" (Pegels, 2010:4945). Therefore, in order to maintain and sustain the environment in a clean and neat way, there should be concerted efforts to reduce and stop the burning of fossil fuels emitting green-house gasses that cause global warming and climate change. As part of collective international community responsibility, the Kyoto Protocol has committed countries that have ratified the Protocol to reduce their emissions (Böhringer, 2003). As part of an effort to reduce emissions is the commitment to change behaviour and technologies toward that which makes possible efficiency in usage (Doppelt, 2009). It is generally accepted that energy efficiency offers a powerful tool for achieving sustainable energy for current and future generations (Omer, 2008). "Improvements in energy efficiency can reduce the need for investment in energy infrastructure, cut fuel costs, increase competitiveness and improve consumer welfare. Environmental benefits can also be achieved by the reduction of greenhouse gases emissions and local air pollution. Energy security can also profit from improved energy efficiency by decreasing the reliance on imported fossil fuels" (ASPO, 2008).

Recognising that buildings can make a major contribution to tackling climate change and energy use, this is the reason why the South African government rolled out the policy on energy efficiency in building (Sebitosi, 2008). Energy efficiency become more important in buildings because buildings account for $40 \%$ of energy consumption in most countries and the absolute figure is rising fast (Laustsen, 2008) as construction booms, especially in developing countries such as China, South Africa, India and so on (Zhou, 2011), and their potential for energy efficiency is huge. As part of energy saving and sustainable energy usage, it has been asserted that "by using adapted insulation and energy savings techniques, up to $80 \%$ of a building's energy consumption for heating or cooling can be saved." As part of the costeffective sustainable energy resource (as well as environmental) conservation model - which in principle changes the human behaviour to reduce demand while not necessarily compromising on value - is the application of improved technologies such as energy-efficient appliances that play a major role in achieving ultimate result in usage (Sebitos, 2008). Therefore, the essence of energy efficiency is to ensure that energy is used to produce the same outcome that would hitherto have been used by orthodox energy to get the same result (Read, 1994). This is because buildings could be turned into climate savers rather than remaining energy wasters (Pears, 2005).

Moreover, there is every reason to embark on energy efficiency in buildings because, in these modern days, as Derek and Clements-Croome (1997) say, "knowledge and technology exist today to slash the energy buildings use, while at the same time improving levels of comfort. By using well-proven energy efficiency measures, 70 to $90 \%$ of a building's energy need for heating or cooling can be cut." Depending on the geographical location of a country, more often than not, heating and cooling are the main energy consumers in buildings (Li \& Colombier, 2009). The use of air conditioner, either for heating or cooling, is estimated to triple before 2030. Most of this energy is wasted due to inadequate insulation (ASPO, 2008). Therefore, the energy policy outlook of South Africa mandates and speaks to all buildings to be energy efficient. This is a welcome approach as part of the strategy to reduce green-house gas and also ensure a sustained environment. "Increasing energy efficiency is seen as the most effective way of improving the security of energy supply, reducing carbon emissions and increasing competitiveness" (Li \& Colombier, 2009). 


\section{Literature Review}

As part of strategy to make energy efficient in South Africa, energy use in buildings has now become one of the priorities for the government, stakeholders and role players. The introduction of the South African Bureau of Standards (SANS) 204 (SANS 204, 2007), standards for energy efficiency in buildings, has brought a remarkable approach to environmental sustainability. Importantly, SANS 204 prescribes enforceable code for energy efficiency in order to limit energy consumption and to ensure that a building does not run out of base electricity-generating capacity (Motau, 2011). "Many buildings in the country do not, at this stage, comply with the minimum requirement levels of SANS 204. This is a good start to set the building industry on the road to energy efficiency" (Motau, 2011).

Wasting energy by using inefficient devices and materials could be as a result of the mind set of business-asusual. According to Motau (2011), "a significant aim of an energy policy is to encourage the use of less energy to provide the same service. It is clear that energy efficiency does not mean simply moving the lights around in your office, but includes everything that involves the use of energy, such as electricity." An organisation's energy policy should focus primarily on energy waste and how this waste can be removed entirely or substantially reduced (Motau, 2011).

Inefficient devices, equipment and materials should be replaced with energy-efficient materials and the "areas that require detailed attention include lighting plug points, server rooms, heaters and air-conditioning units, among others. If the electricity use is firstly considered, there is a high chance for significant financial benefit to the business, and environmental benefit to the broader society" (Motau, 2011). There are many possibilities in terms of energy policy, which could have a significant impact on sustainable development aims. "What you invest in environmentally sound energy practices today will pay itself back tomorrow" (Motau, 2011).

As part of the energy efficiency strategy of the government, the new policy guidelines prescribe that all buildings would have to be fitted with renewable energy water-heating systems to avoid sanction (Njobeni, 2012). There have been scientific predictions that South Africa will run into electricity supply constraints in the future if the country does not embrace efficient use of energy, and this calls for the deployment of alternative energy and efficient devices and appliances in all buildings. Pursuant to this, there is an urgent need to reduce electricity consumption through energy efficiency. Undoubtedly, scientific evidence has also proven that energy efficiency is a quicker and cheaper alternative (Wilkinson et al., 2007). Pursuant to this, older buildings are the major targets for efficiency as they are mostly considered as energy inefficient.

The Department of Trade and Industry crucially considers environmental sustainability of buildings, hence it has published a sub-regulation to the National Building Regulation and Building Standards Act. This Act requires all buildings to be fitted with renewable energy water heating systems, such as solar water-heating systems (NBR, 2008). However, alternative energy systems such as water-heating systems that are being fixed must meet and comply with the South African National Standards. Solar water-heating systems will also have to comply with the South African National Standards. More importantly, the regulations prescribed that devices such as heaters, air-conditioners and mechanical ventilation systems will have to be energy efficient. Consequently, before approval is sought for any building, whether new or refurbished, the layout drawings have to show the location and capacity of water-heating installations and details of the required insulation. The Department of Trade has emphasised that "the energy efficient regulation for residential and commercial buildings, places of learning and worship, certain medical clinics and other categories of buildings will make it compulsory for all new buildings to be designed and constructed to a standard that will make it possible for the user to minimise the energy required to meet the functional requirements," the department said. The Department of Energy has also demonstrated the willingness to be part of the solution and said that it will roll-out and distribute one million solar water heaters by 2014 in order to reduce the burden of water heating on the national electricity grid.

\section{Reducing the Impacts of Climate Change through Energy Efficiency in Buildings}

In ordered to reduce the impact of global climate change, the South African government set a "standard for a National Mode of Acceptable Practice for Cost, Energy and Environmentally Effective Building Design, Construction, Operation and Maintenance, Products, Systems and Professional Services be developed according to the targets outlined in the National Energy Efficiency Strategy for South Africa set by South African Department of Minerals and Energy" (SANS, 2007). This standard for energy efficiency in buildings was set against the backdrop that "the consumption of finite resources should be reduced in order to ensure a transition to renewable resources; $\mathrm{CO}_{2}$ and other pollutants need to be reduced substantially; running costs of buildings must be controlled; the structure of buildings should be protected and preserved; value is added through energy efficiency measures; comfort can be enhanced; productivity and 
competitiveness can be improved; sustainable jobs are created while the existing infrastructure is retained" (SANS, 2007).

The importance of this is to ensure that buildings are built in energy efficient ways and manners by using energy effectively and source sustainable energy. It is therefore incumbent on building owners to comply with the regulations by ensuring that their building designs and lay-outs "incorporate into their design all latest Demand Side Management (DSM) programs available in order to reduce the building maximum demand and the electrical energy consumption" (SANS, 2007). This is the reason why the regulations advocate responsible energy use and to this end prescribe, in terms of section 4.7, that the responsible person shall ensure that the use of renewable energy sources in buildings is maximized.

It is therefore pertinent to point out that emissions from energy use in buildings are also major contributions to global climate change. Virtually all the national and international instruments, and in particular the Kyoto Protocol, prescribed various ambitious targets for emissions reduction. The building sector presents a huge challenge in achieving these targets because of the massive consumptions of energy by them (Li \& Colombier, 2009). Pursuant to this, there is need to implement and enforce energy-efficiency regulations as articulated by Lee and Yik (2004), thus "enforcing energy efficiency through regulatory control has the advantage that all parties concerned will be aware of the requirements, and ensures that a certain minimum level of performance is achieved across the board" (Lee \& Yik, 2004).

In South Africa, coal is the major source of energy use, especially for electricity, and virtually everyone relies on it both for domestic and industrial activities. This seems it is not likely to stop anytime soon. Undoubtedly, when coal is burnt to generate electricity, the emissions from the burning impact on the environment and cause global change (Stracher \& Taylor, 2004). Therefore, the potent resource to mitigate and address this is energy efficiency resource, especially in buildings where there are huge consumptions of electricity and other energy (Brennan \& Palmer, 2013). The life span of a house or building is aggregated between 30-50 years before being demolished and reconstructed (Méquignon et al. 2013). If there are inefficient buildings, such will have tremendous impact on the environment during their lifespan (Darko et al., 2013). Carbon-emissions mitigations in building is beneficial, especially for the low-income household (Brown \& Southworth, 2006) because it "increased access to energy services, improved indoor and outdoor air quality, as well as increased comfort, health and quality of life, job creation and economic competitiveness" (Li \& Colombier, 2009). And, as such, proponents of energy-efficient buildings have argued that it is one of the least-costly approaches to mitigating greenhouse gas emissions by designing and constructing a climate-friendly built environment and how buildings are linked with other socio-economic amenities and infrastructures (Reddy, 2010). With these approaches, the combination of green buildings and smart growth could deliver the deeper reductions that are needed to mitigate climate change (Seyfang, 2010).

Literature on energy efficiency clearly points out that energy-efficient buildings do not necessarily cost more than less-efficient ones when using a life-cycle analysis approach (Gillingham, 2009). The energy component of the future built environment will continue to stress the need for energy efficiency in buildings as panacea for the scourge of climate change (Darby, 2006).

\section{Conclusion}

Inaction against global climate change caused by emissions is very dangerous because it can lead to an unimaginable catastrophe and there are consequences for this. The massive drive for alternative energy and energy efficiency has proven to be powerful and perfect tools for mitigating global emissions. South Africa has joined the emissions-reduction bandwagon by, in addition to its various international obligations, rolling out implementable standards and regulations that mandate and compel energy efficiency in buildings. This is against the backdrop that emissions from buildings are also major sources of global warming causing climate change. These initiatives at domestic level are welcome and other countries are enjoined to emulate them.

\section{Recommendations}

International and national scientific reports have indicated that the African continent is vulnerable to the impact of climate change and that it does not have the technological know-how or capacity to adapt. The use of energy efficiency in buildings presents a potent strategy to reduce carbon emissions. Similarly, the use of alternative energy is also a good approach to mitigate carbon missions. Accordingly, regulations and standards have since been prescribed and provided by regulatory authorities. It is therefore incumbent upon role players to embrace them. Non-compliance should be met with the stringent sanctions. At the same time, there is need for awareness to be created so that people can know about 
the standard, regulations and consequences for non-compliance. Those who are entrusted with building approval must ensure that the designs and layouts conform to the standards set in the codes. But they should not stop at that, during construction, there should be close monitoring and assessment of all the devices installed. They must comply and be in line with what had been approved. Deviation from the approved plan should be sanctioned forthwith and both the civil and criminal responsibilities of the erring owner and contractor should be explored to the appropriate tribunal. Energyefficiency use should be the general standard without exception in view of the predicted devastating and catastrophe of the bizarre climate events.

\section{References}

Warburton C, A Gilder, S Shabalala 2007. Options for Greenhouse Gas Mitigation Mechanisms in South African Legislation. From http://www.basicproject.net/data/final/Paper12South\%20Africa\%20Legislative\%200ptions\%20for\%20GHG\%20Mitigation\%85.pdf. (Retrieved on 9 July, 2013).

Lee WL, Yik FWH 2004. Regulatory and voluntary approaches for enhancing building energy efficiency.. Progress in Energy and Combustion Science. 30(5): 477-499.

ASPO 2008. Energy efficiency in buildings, http://www.isover.com/our-commitment-to-sustainability/energy-efficiency/energy-efficiencyin-buildings. From http://www.isover.com/our-commitment-to-sustainability/energy-efficiency/the-global-energy-and-climatechallenge energy efficiency in buildings. (Retrieved on 9 July, 2013).

Costa A, Marcus M. Keane, J. Ignacio Torrens, Edward Corry 2013. Building operation and energy performance: Monitoring, analysis and optimisation toolkit Applied Energy. Sustainable Development of Energy, Water and Environment Systems. 101: 310-316.

Pegels A 2010. Renewable energy in South Africa: Potentials, barriers and options for support. Energy Policy. 38(9): 4945-4954.

Davidson OR, Sokona Y 2002. new sustainable energy path for African development: Think bigger act faster. From http://www.eri. uct.ac.za/Research/publications-pre2004/02Davidson-Sokona_Think_bigger.pdf. (Retrieved on 9 July, 2013).

Davidson OR, Sokona Y, 2002. new sustainable energy path for African development: Think bigger act faster. From . http://www.eri.uct.ac.za/Research/publications-pre2004/02Davidson-Sokona_Think_bigger.pdf. (Retrieved on 29 March, 2013).

Simms A, Murphy M 2005. Africa Up in Smoke: The second report from the working group on climate change and development. Oxfam Policy and Practice: Climate Change and Resilience, 1(1): 58-101.

Brecha RJ 2008. Emission scenarios in the face of fossil-fuel peaking. Energy Policy. 36(9): 3492-3504.

Rotmans J 1997. Indicators for sustainable development. The Press Syndicate of University of Cambridge, Cambridge, UK.

Dryzek JS 2013. The politics of the earth: Environmental discourses. Oxford University Press, Oxford, UK.

Clapp J, Dauvergne P 2008. Paths to a Green World The Political Economy of the Global Environment. Academic Foundation, New Delhi, India.

Böhringer C 2003. The Kyoto protocol: a review and perspectives. Oxford Review of Economic Policy, 2003. Oxford Review of Economic Policy. 9(3): 451-466.

Doppelt D 2009. Leading Change Toward Sustainability-: A Change-Management Guide for Business, Government and Civil Society. Greenleaf Publishing Ltd, Sheffield, UK.

Omer AM 2008. Energy, environment and sustainable development. Renewable and Sustainable Energy Reviews, 12(9): 2265-2300.

Sebitosi AB 2008. Energy efficiency, security of supply and the environment in South Africa: Moving beyond the strategy documents. Energy, 33(11):1591-1596.

Laustsen J 2008. Energy efficiency requirements in building codes, energy efficiency policies for new buildings - International Energy Agency (IEA). http://www.energie-cluster.ch/ecweb5/de/wissenstransfer/innovationsgruppen/ig-peg/forschung-und-entwicklung/ efficient buildings iea_2008.pdf. (Retrieved on 2 February, 2013).

Zhou N 2011. China's Energy and Carbon Emissions Outlook to 2050. Lawrence Berkeley National Laboratory. http://escholarship.org/uclitem/4sz7t1tt\#page-3. (Retrieved on 29 March, 2013).

Read P 1994. Responding to global warming: the technology, economics and politics of sustainable energy. Zed Books, London, UK.

Pears A 2005. Potential for Replacing Hazelwood with Alternatives, Particularly Energy Efficiency. From http://www.naturaledgeproject. net/Documents/replacinghazelwoodwithalternativesfinal1a.pdf. (Retrieved on 9 April, 2013).

Derek T, Clements-Croome J 1997. What do we mean by intelligent buildings? Automation in Construction. 6( 5-6): 395-400.

Li J, Colombier M 2009. Managing carbon emissions in China through building energy efficiency . Journal of Environmental Management. 90( 8): 2436-2447.

Motau D 2011. New code a good start for setting building industry on energy efficiency course, October 14, 2011. From http://www.engineeringnews.co.za/article/implementable-energy-policies-needed-2011-10-14. (Retrieved on 19 August, 2013).

Njobeni S 2012. New buildings must follow energy laws. From http://www.bdlive.co.za/articles/2010/06/15/new-buildings-must-followenergy-laws;;sessionid=BD66F9A95DC3ECF02E396502BA886390.present2.bdfm. (Retrieved on 1 August, 2013).

Wilkinson P, Kirk R Smith, Sean Beevers, Cathryn Tonne, Tadj Oreszczyn 2007. Energy, energy efficiency, and the built environment. The Lancet, 370(9593): 1175-1187.

Stracher GB, Taylor TP 2004. Coal fires burning out of control around the world: thermodynamic recipe for environmental catastrophe. International Journal of Coal Geology. 59( 1-2): 7-17. 
Brennan JJ, Palmer KL 2013. Energy efficiency resource standards: Economics and policy. Utilities Policy. 25: 58-68.

Mequignon M, Adolphe L, Thellier F, Ait Haddou H 2013. Impact of the lifespan of building external walls on greenhouse gas index. Building and Environment, 59:654-661.

Darko E K, Niaizi NZ, Scott A, Varsha D, Lakshmi KV 2013. The Construction Industry and Lifespan Green building: case study. From map-sa.net. http://map-sa.net/docs/20140709-11-12-07.pdf. (Retrieved on 16 October, 2013).

Brown MA, Southworth F 2006. Mitigating climate change through green buildings and smart growth. - smartech.gatech.edu. From https://smartech.gatech.edu/handle/1853/23806. (Retrieved on 14 September, 2013).

Reddy BS, Hasselmann MSF, Assenza GB, Assenza D 2010. Energy efficiency and climate change: conserving power for a sustainable future. Sage Publication, New Delhi, India.

Seyfang G 2010. Community action for sustainable housing: Building a low-carbon future. Energy Policy. 38(12): 7624-7633.

Gillingham K, Newell RG, Palmer K 2009. Energy efficiency economics and policy. From http://www.nber.org/papers/w15031. (Retrieved on 25 November, 2013).

Darby S 2006. The effectiveness of feedback on energy consumption. http://www2.z3controls.com/doc/ECl-Effectiveness-ofFeedback.pdf. (Retrieved on 21 November, 2013). 